\title{
A surgical challenge: Idiopathic scrotal elephantiasis
}

\author{
Hilary Laurel Brotherhood, MD; ${ }^{*}$ Michael Metcalfe, MD; Larry Goldenberg, MD, FRCSC; \\ Peter Pommerville, MD, FRCSC; Cameran Bowman, MD; ${ }^{+}$David Naysmith, $\mathrm{MD}^{+}$
}

"Department of Urological Sciences, University of British Columbia, Vancouver, BC; 'Division of Plastic Surgery, Department of Surgery, University of British Columbia, Vancouver, BC

Cite as: Can Urol Assoc J 2014;8(7-8):e500-4. http://dx.doi.org/10.5489/cuaj.1739

Published online July 18, 2014.

\section{Abstract}

Scrotal elephantiasis is a condition rarely encountered in developed nations. It is endemic in tropical regions due to the presence of filariasis (Wucheria bancrofti). We report 2 cases of idiopathic scrotal elephantiasis in Canadian citizens with no history of travel to endemic filariasis regions, malignancy, surgery or radiation. Both patients underwent complete excision of the involved tissue with reconstruction. We found that for advanced cases of scrotal lymphedema, surgery is currently the only solution. In our cases of advanced idiopathic disease, surgical treatment combining the expertise of a plastic surgeon and a urologist provided a successful functional and cosmetic result.

\section{Introduction}

Scrotal elephantiasis is a condition characterized by massive scrotal lymphedema with gross genital deformation. ${ }^{1}$ It is rarely encountered in developed nations; it occurs in tropical regions where filariasis (Wucheria bancrofti) is endemic. Although not life-threatening, chronic lymphedema is disabling with significant physical and psychological morbidity and complications, including impaired hygiene, urinary incontinence and immobility. Reporting of scrotal elephantiasis in industrialized countries is limited to a small number of case reports, mostly attributed to surgery, irradiation or malignancy. ${ }^{2,3}$ Reported methods of surgical reconstruction involve either lymphangioplasty or complete excision of lymphedematous tissue with local tissue reconstruction.

We report 2 cases of idiopathic scrotal elephantiasis in Canadian citizens with no history of travel to endemic filariasis regions, malignancy, surgery or radiation. Both patients underwent complete excision of the involved tissue with reconstruction.

\section{Case 1}

A 65-year-old morbidly obese male presented with penile and bilateral scrotal swelling with resultant difficulties with hygiene, mobilization and general discomfort. He had no history of travel to endemic regions, malignancy, infection or radiation. His medical history was limited to a remote cholecystectomy and non-insulin dependent diabetes mellitus. Medications included aspirin, metformin, glyburide, irbesartan and rosiglitazone.

Physical examination showed an obese male with large abdominal pannus and a scrotum about the size of a soccer ball. The testicles could not be appreciated and the penis could not be visualized as it was completely buried in the scrotum (Fig. 1, part A). The scrotal skin was very thick, and hardened with fixed lymphedema, though the dorsal and lateral skin was a bit softer and appeared more normal.

The hematology profile and electrolyte panel were normal, except for evidence of chronic diabetic nephropathy (estimated glomerular filtration rate $67 \mathrm{~mL} / \mathrm{min} / 1.73 \mathrm{~m}^{2}$ ). The $\operatorname{lgG}$ and $\lg$ E were elevated at $16.90 \mathrm{~g} / \mathrm{L}$ (7.51-15.60) and 2198 ug/L (1-396), respectively. The inflammatory markers erythrocyte sedimentation rate and C-reactive protein were both elevated at $10.9 \mathrm{mg} / \mathrm{L}(0-2.0)$ and $18 \mathrm{~mm} / \mathrm{h}(0-10)$, respectively. The antinuclear antibodies titre was weakly positive at 1:80. Albumin was marginally decreased at $35 \mathrm{~g} / \mathrm{L}$ (38-53), while total protein was normal at $73 \mathrm{~g} / \mathrm{L}$ ). IgM, thyroid-stimulating hormone, lactate dehydrogenase, creatine phosphokinase, troponin, liver enzymes, bilirubin were within normal limits. Filarial serology was negative.

The patient exceeded the size limit of the magnetic resonance imaging scanner. Abdominal-pelvic computed tomography showed no evidence of lymphadenopathy or malignancy throughout abdomen and pelvis in keeping with idiopathic scrotal elephantiasis.

The patient underwent surgical excision of the edematous subcutaneous tissues and reconstruction of his penis and scrotum with multiple scrotal flaps and a skin graft of the penis (Fig. 1, parts B and C). After excising the large 


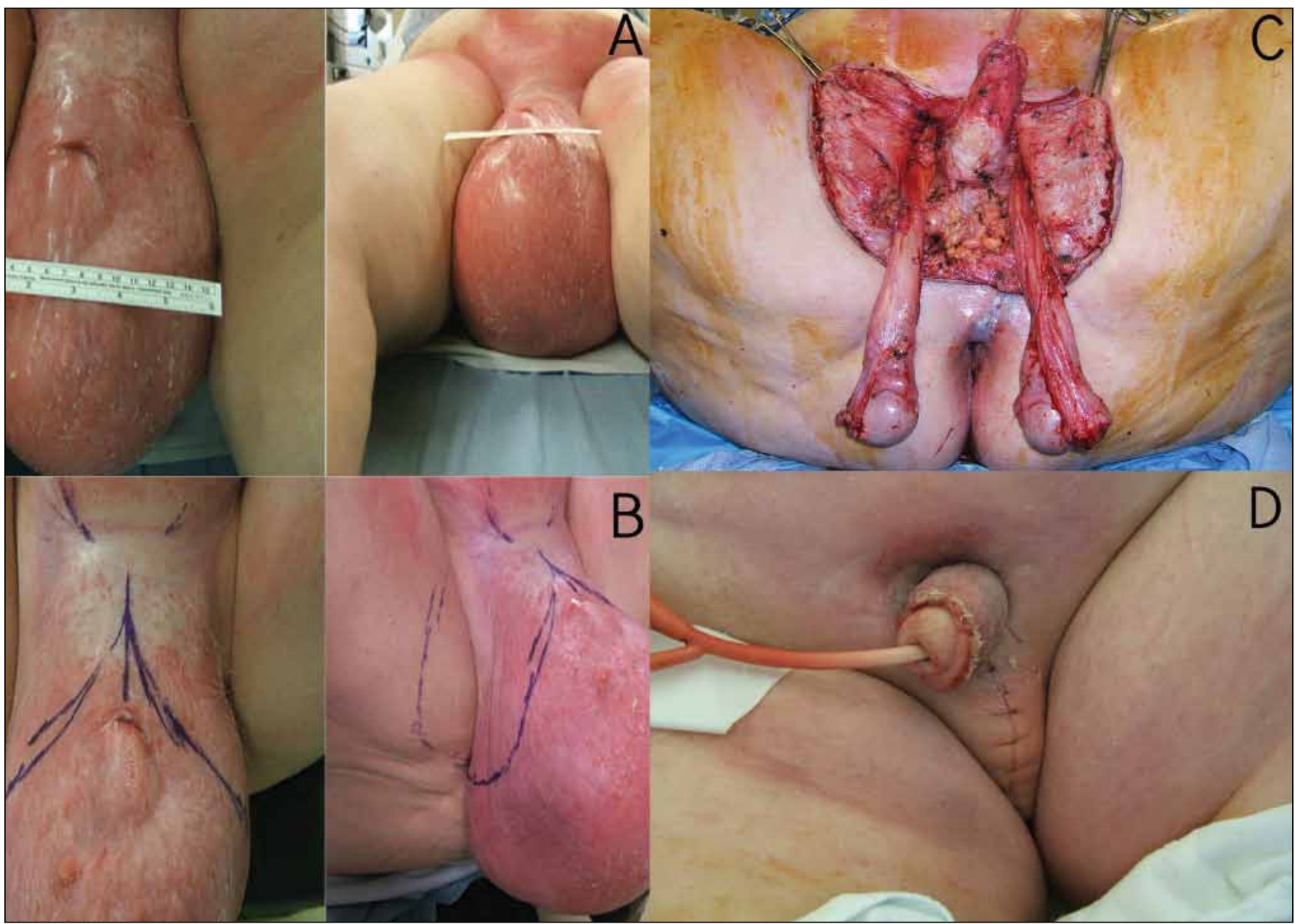

Fig. 1. Case 1. A\&B: preoperative; C: intra-operative; and D: postoperative.

redundant, edematous scrotum, the penis was found and was dissected out with a circumcising incision around the corona and down to the base. After dilation of a urethral stricture, a catheter was inserted and bilateral orchidopexy was performed. Scrotal reconstruction was then undertaken using 2 laterally based scrotal flaps of the most normal skin available. These were closed along the midline and circumferentially around the base of the penis. A split thickness skin graft of the anterior thigh, harvested at 12 to 14th thousandths of an inch, was then used to cloak the penis. It was meshed and applied with a tie-over dressing. The ventral penis was the seam of the graft (Fig. 1, part D).

In our patient, no postoperative complications occurred and the patient was very pleased with the functional and cosmetic improvement. The scrotum healed well and he was able to urinate without difficulty. Three months after his operation, he had an abdominal lipectomy as the pannus was resting on the reconstructed penis and scrotum, causing excoriation. At 7 months postoperatively ( 4 months post-lipectomy), the scrotal reconstruction showed a stable midline closure and no further lymphedema (Fig. 3, part A). At 1 year follow-up, there have been no recurrence of symptoms.

\section{Case 2}

In 2006, a 43-year-old morbidly obese male with a 10-year history of increasing lower extremity and severe scrotal edema presented with a mass in the left testicle. Scrotal ultrasound confirmed a hydrocele. When he saw a urologist in 2007, it had progressed to bilateral hydroceles. In 2008 he had a hydrocelectomy, and a repeat procedure in 2010. In 2011 his symptoms severely progressed with the scrotum swelling below his knees and his penis completely buried in the scrotum. He had to urinate in the bathtub and was using a rifle cleaner to clean the buried sinus to his urethra.

There was no history of malignancy, infection, or radiation and no evidence of filariasis. His medical history included morbid obesity, non-insulin dependent diabetes mellitus, hypercholesterolemia and hypertension. Medications included metformin, aspirin, rosuvastatin and amlodipine. 


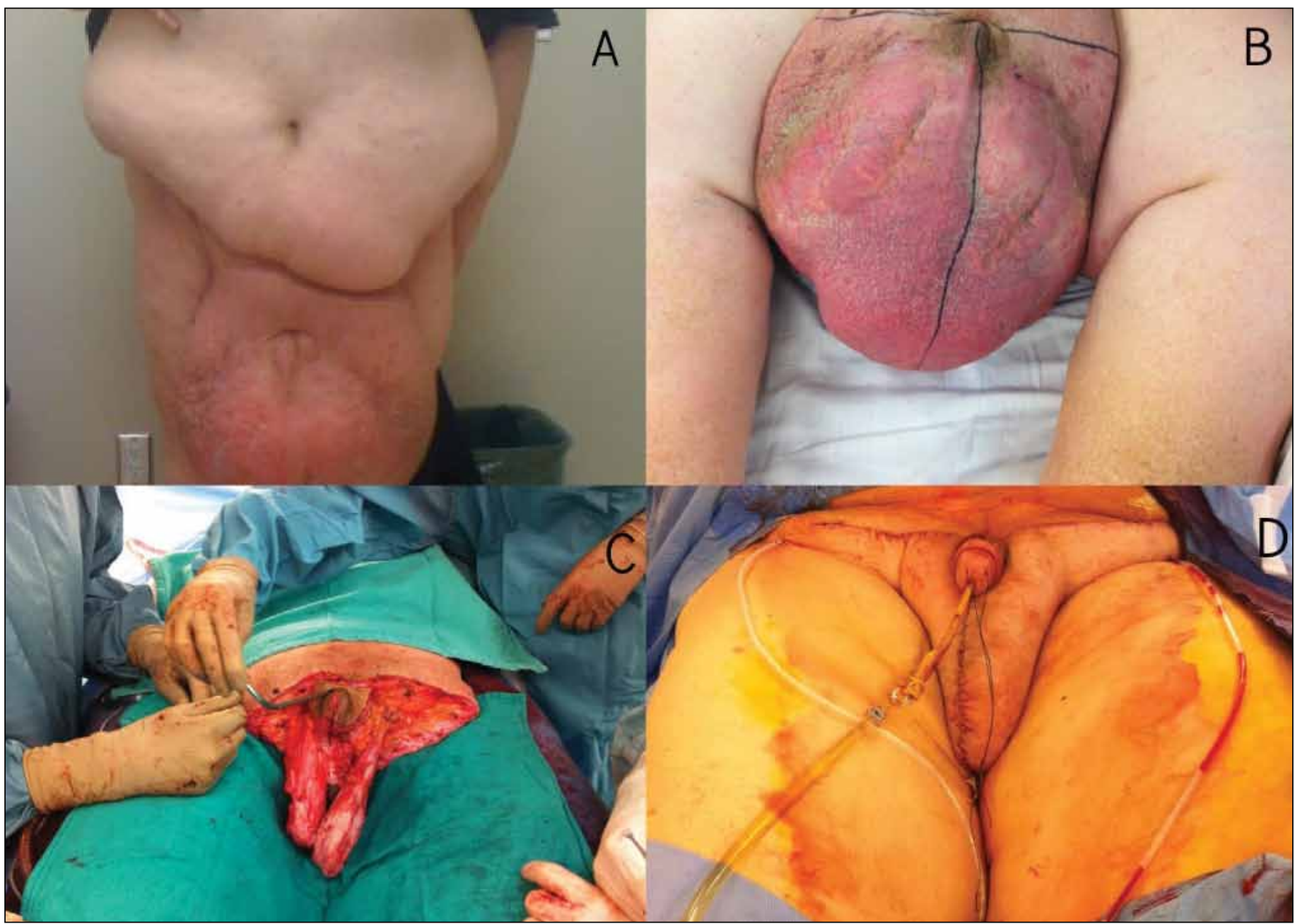

Fig. 2. Case 2. A\&B: preoperative; C: intra-operative; instrument showing sinus to urethra; and D: postoperative.

Physically, he was 6 feet tall and 475 pounds. There was an extremely large abdominal pannus and a secondary suprapubic pannus, which extended to his knees (Fig. 2, part A). The skin was rugated and erythematous, with no indication of infection or excoriation. There was a small anterior midline opening on the suprapubic pannus $2.5 \mathrm{~cm}$ below the pubic symphysis that was a sinus to his urethra (Fig. 2, part B). There was no discharge or erythema, but there was a foul odour. The scrotum extended to the level of his tibia. The skin was thickened, ruggated and erythematous with significant pitting edema. His hair follicles were about $1 \mathrm{~cm}$ apart. The testicles were non-palpable. A computed tomography scan showed no intra-abdominal pathology, and did not show the testes.

The patient was taken to the operating room for partial scrotectomy, partial panniculectomy, bilateral fasciocutaneous advancement flaps for scrotal reconstruction, and an advancement flap for penile reconstruction.

A catheter was unable to be placed. Through a midline Raphae incision, dissection with electrocautery revealed several loculated fluid collections of $0.5 \mathrm{~L}$ of fluid bilaterally. On the right side, the spermatic cord was identified with significant scar tissue, and the vas deferens palpated within. The testicle was dissected from the scrotal tissue and no tunica vaginallis was identified. The spermatic cord was dissected up to the external ring, no hernia sac was seen, and the ring was closed. In total, $3 \mathrm{~kg}$ of tissue was removed on the right side. The same technique was undertaken on the left side with the same results, leading to a total of $6 \mathrm{~kg}$ of tissue being removed from the scrotum (Fig. 2, part C).

The penis was exposed by incising the pannus midline from the penile sinus superiorly, revealing a degloved and inverted penile shaft skin tethered only by $2 \mathrm{~cm}$ on its ventral side. At this point, a catheter was inserted and a pannulectomy was performed. The superior portion was thinned and prepared for a penile advancement flap. Two posterior lateral flaps were created and thinned for scrotal advancement flaps. These were sutured together in the midline over the testes. A residual $2 \mathrm{~kg}$ of tissue was removed and the lateral portions were closed. The inverted penis was then freed of 


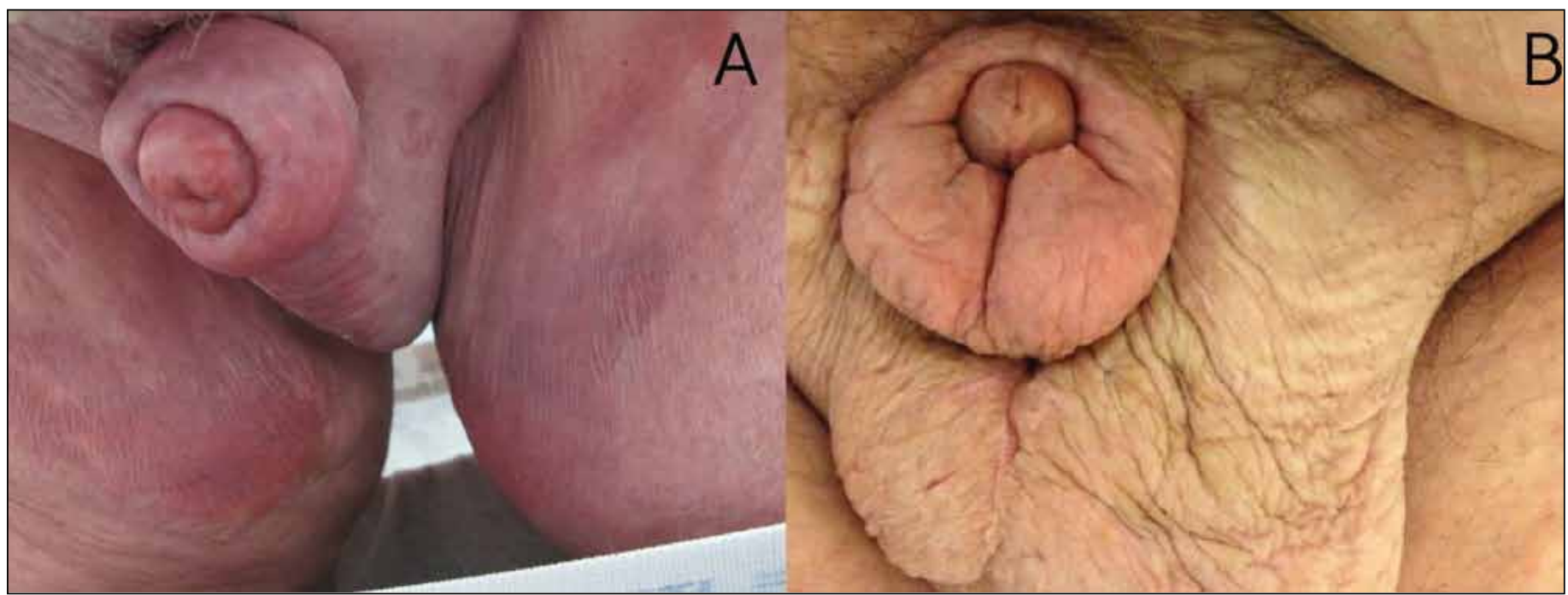

Fig. 3. A: Case 1 at the 7-month follow-up and B: case 2 at the 9-month follow-up.

excess tissue on dorsal portion, sutured and then anchored to Buck's fascia at 2- and 10-O'clock and a third suture at 12- O'clock to periosteum. Each remaining hemi-pannus was advanced around the penis and sutured to the midline scrotum, and to the base of the penis. Two drains were placed below the flaps and a Penrose drain in the dependent scrotum (Fig. 2, part D). A wound vac was applied. The estimated blood loss was 800 cc.

On postoperative day 1 , a scrotal ultrasound and flap Doppler ultrasound showed good flow. On day 5, The Foley catheter was removed and the patient voided well. The adherent flaps appeared healthy; however, an infection developed at the base of the penis. Cultures showed Phallus Epidermolysis secondary to pseudomonas, and appropriate intravenous antibiotics were administered. The patient returned to the operating room on day 13 for debridement and split-thickness skin grafting to the dorsum of penis, and application of a wound vac. On day 18, the wound vac was removed, but the dorsal surface of the graft was not adherent. On day 26, the patient was discharged with the dorsal surface healing by secondary intention. At the 9-month follow-up, the patient had no recurrence of lymphedema and is pleased with his functional and cosmetic result (Fig. 3, part B).

\section{Discussion}

In 1820, Delpech described a surgical treatment for genital elephantiasis, involving complete excision of all lymphedematous skin and subcutaneous tissue of the penis and scrotum; this was followed by split-thickness skin grafting to the penis and advancement flaps of uninvolved posterior perineal skin to reconstruct the scrotum. ${ }^{4}$ The alternative treatment described in the literature is lymphangioplasty $y^{5,6}$ and lymphaticovenous anastomasosis. ${ }^{7}$ This excision is also termed "the physiological approach" 8 and it is applicable to reversible states (i.e., reversible skin changes) of minor lymph stasis and easily identifiable lymphatic obstruction. It involves the re-establishment of new lymphatic channels before fibrosis occurs. However, as in the case of our 2 patients who both presented with chronic fibrosis, suitable lymphatic channels may not be present. For this reason, the excisional surgical repair was the approach deemed to provide the most successful result.

In a report of 350 men with filarial genital lymphedema, all patients underwent surgical excision of lymphedematous tissue with split thickness skin graft to the penile shaft and scrotal reconstruction with advancement flaps; this report yielded an overall complication rate of $19.4 \%{ }^{8}$ This included a $10.2 \%$ rate of infection, $8.2 \%$ rate of hematoma and $7.3 \%$ recurrence of lymphedema, which the authors attributed to discontinuation of antifilarial drugs. ${ }^{8}$ In one of our patients, a postoperative infection occurred, which was successfully treated with debridement, antibiotics and a wound vac. Patient factors that may have contributed to this result include obesity and diabetes mellitus.

\section{Conclusion}

Both of our patients were satisfied with their results and neither has had a recurrence of the lymphedema. Technical points that likely contributed to this result include the complete dissection of all involved tissue, the appearance of diligent hemostasis, the use of hemovac drains to prevent fluid re-accumulation split-thickness skin grafting on the ventral surface of the penis, and the taking of scrotal advancement flaps from areas with normal, non-edematous skin. Excisional surgical treatment combining the expertise of a 
Brotherhood et al.

plastic surgeon and a urologist provides a successful functional and cosmetic result in highly incapacitated patients.

Competing interests: Dr. Brotherhood, Dr. Metcalfe, Dr. Pommerville and Dr. Bowman all declare no competing financial or personal interests. Dr. Goldenberg has received consultant fees from Amgen, Eli Lilly Canada and Abbott Canada.

This paper has been peer-reviewed.

\section{References}

1. Cook G. Manson's Tropical Disease. 2nd edition (International Student Edition). London, UK: WB Saunders; 1998:1322-38.

2. Dianzani C, Gaspardini F, Persichetti P, et al. Giant scrotal elephantiasis: an idiopathic case. Int J Immunopath Pharm 2010;23:369-72.
3. Martinez RE, Couchell SH, Raffel B, et al. Primary lymphedema of the scrotum: Surgical treatment and reconstruction. Ann Plast Surg 1988;21:354-7. http://dx.doi.org/10.1097/00000637-19881000000010

4. Gibson T: Delpech: His contributions to plastic surgery and the astonishing cases of scrotal elephantiasis. Br K Plast Surg 1956;6:4-10. http://dx.doi.org/10.1016/S0007-1226(53)80003-2

5. Baumeister $R G$, Siuda $S$. Treatment of lymphedemas by microsurgical lymphatic grafting: What is proved? Plast Reconstr Surg 1990;85:64-74. http://dx.doi.org/10.1097/00006534-199001000-00012

6. Gillies H, Frazier FR. Treatment of lymphedema by plastic operation. Br Med J 1935;96:96-9. http:// dx.doi.org/10.1136/bmi.1.3863.96

7. Huang GK. Microsurgical therapy of scrotum elephantiasis. Z Urol Nephrol 1989;82:459-62.

8. Dandapat MC, Mohapatro SN, Petro SK. Elephantiasis of penis and scrotum. Am J Surg 1985;149:686-90. http://dx.doi.org/10.1016/S0002-9610(85)80156-2

Correspondence: Dr. Hilary Laurel Brotherhood, Department of Urological Sciences, University of British Columbia, Vancouver, BC; hilarybrotherhood@gmail.com 